\title{
Glucose effectiveness, but not insulin sensitivity, is improved after short-term interval training in individuals with type 2 diabetes mellitus: a controlled, randomised, crossover trial
}

\author{
Kristian Karstoft ${ }^{1,2}$ (1) $\cdot$ Margaret A. Clark $^{1}$ - Ida Jakobsen ${ }^{1}$ - Sine H. Knudsen ${ }^{1}$. \\ Gerrit van Hall $^{3}$ - Bente K. Pedersen ${ }^{1}$. Thomas P. J. Solomon ${ }^{4,5}$
}

Received: 4 May 2017 / Accepted: 14 July 2017 / Published online: 25 August 2017

(C) Springer-Verlag GmbH Germany 2017

\begin{abstract}
Aims/hypothesis The role of glucose effectiveness $\left(S_{\mathrm{G}}\right)$ in training-induced improvements in glucose metabolism in individuals with type 2 diabetes is unknown. The objectives and primary outcomes of this study were: (1) to assess the efficacy of interval walking training (IWT) and continuous walking training $(\mathrm{CWT})$ on $S_{\mathrm{G}}$ and insulin sensitivity $\left(S_{\mathrm{I}}\right)$ in individuals with type 2 diabetes; and (2) to assess the association of changes in $S_{\mathrm{G}}$ and $S_{\mathrm{I}}$ with changes in glycaemic control. Methods Fourteen participants with type 2 diabetes underwent three trials (IWT, CWT and no training) in a crossover study. Exclusion criteria were exogenous insulin treatment, smoking, pregnancy, contraindications to structured physical activity and participation in recurrent training ( $>90 \mathrm{~min} /$ week). The trials were performed in a randomised order (computerised-generated randomisation). IWT and CWT consisted of ten supervised treadmill walking sessions, each lasting 60 min, over 2 weeks.
\end{abstract}

Kristian Karstoft

k_karstoft@dadlnet.dk

1 The Centre of Inflammation and Metabolism and the Centre for Physical Activity Research, University of Copenhagen,

Rigshospitalet, Section M7641, Blegdamsvej 9,

DK-2100 Copenhagen, Denmark

2 Department of Clinical Pharmacology, Bispebjerg Hospital, Copenhagen, Denmark

3 Clinical Metabolomics Core Facility, Clinical Biochemistry, Rigshospitalet, Department of Biomedical Sciences, Copenhagen, Denmark

4 School of Sport, Exercise, and Rehabilitation Sciences, University of Birmingham, Birmingham, UK

5 Institute of Metabolism and Systems Research (IMSR), University of Birmingham, Birmingham, UK
IWT was performed as repeated cycles of 3 min slow walking and 3 min fast walking (aiming for $54 \%$ and $89 \%$ of $\dot{V} \mathrm{O}_{2 p e a k}$, respectively, which was measured during the last minute of each interval), and CWT was performed aiming for a moderate walking speed ( $73 \%$ of $\left.\dot{V} \mathrm{O}_{2 p e a k}\right)$. A two-step (pancreatic and hyperinsulinaemic) hyperglycaemic clamp was implemented before and after each trial. All data were collected in a hospitalised setting. Neither participants nor assessors were blinded to the trial interventions.

Results Thirteen individuals completed all procedures and were included in the analyses. IWT improved $S_{\mathrm{G}}$ (mean \pm SEM: $\left.0.6 \pm 0.1 \mathrm{mg} \mathrm{kg}^{-1} \mathrm{~min}^{-1}, p<0.05\right)$ but not $S_{\mathrm{I}}$ $(p>0.05)$, whereas CWT matched for energy expenditure and time duration improved neither $S_{\mathrm{G}}$ nor $S_{\mathrm{I}}$ (both $p>0.05$ ). Changes in $S_{\mathrm{G}}$, but not in $S_{\mathrm{I}}$, were associated with changes in mean $\left(\beta=-0.62 \pm 0.23, r^{2}=0.17, p<0.01\right)$ and maximum $\left(\beta=-1.18 \pm 0.52, r^{2}=0.12, p<0.05\right)$ glucose levels during $24 \mathrm{~h}$ continuous glucose monitoring.

Conclusions/interpretation Two weeks of IWT, but not CWT, improves $S_{\mathrm{G}}$ but not $S_{\mathrm{I}}$ in individuals with type 2 diabetes. Moreover, changes in $S_{\mathrm{G}}$ are associated with changes in glycaemic control. Therefore, increased $S_{\mathrm{G}}$ is likely an important mechanism by which training improves glycaemic control in individuals with type 2 diabetes.

Trial registration: ClinicalTrials.gov NCT02320526

Funding: CFAS is supported by a grant from TrygFonden. During the study period, the Centre of Inflammation and Metabolism (CIM) was supported by a grant from the Danish National Research Foundation (DNRF55). The study was further supported by grants from Diabetesforeningen, Augustinusfonden and Krista og Viggo Petersens Fond. CIM/CFAS is a member of DD2-the Danish Center for Strategic Research in Type 2 Diabetes (the Danish Council for Strategic Research, grant no. 09-067009 and 09-075724). 
Keywords Continuous glucose monitoring - Exercise interventions · Glucose effectiveness · Hyperglycaemic clamp · Hyperinsulinaemic clamp · Insulin sensitivity . Lifestyle intervention(s) $\cdot$ Mass action of glucose $\cdot$ Pancreatic clamp · Training

$\begin{array}{ll}\text { Abbreviations } \\ \text { CGM } & \text { Continuous glucose monitoring } \\ \text { CWT } & \text { Continuous walking training } \\ \text { GIR } & \text { Glucose infusion rate } \\ \text { IWT } & \text { Interval walking training } \\ R_{\mathrm{a}} & \text { Rate of glucose appearance } \\ R_{\mathrm{aENDO}} & \text { Endogenous rate of glucose appearance } \\ R_{\mathrm{aTOTAL}} & \text { Total rate of glucose appearance } \\ R_{\mathrm{d}} & \text { Rate of glucose disappearance } \\ \text { RER } & \text { Respiratory exchange ratio } \\ S_{\mathrm{G}} & \text { Glucose effectiveness } \\ S_{\mathrm{I}} & \text { Insulin sensitivity }\end{array}$

\section{Introduction}

Exercise training improves glycaemic control in individuals with type 2 diabetes [1], with reductions in postprandial glucose levels being the most pronounced $[2,3]$. These reductions are most often ascribed to increased peripheral tissue glucose disposal [4, 5], and may be dependent on increased peripheral insulin sensitivity $\left(S_{\mathrm{I}}\right)$ and/or increased glucose effectiveness [6] $\left(S_{\mathrm{G}}\right.$; defined as the ability of glucose per se to stimulate its own uptake and to suppress its own production [7]). However, the relative contribution of these mechanisms towards improved glycaemic control is unknown.

It has been known for many years that acute exercise improves $S_{\mathrm{I}}[8]$ and that training improves $S_{\mathrm{I}}$ in individuals with type 2 diabetes [9]. However, since $S_{\mathrm{I}}$ increases with weight loss, some of the training-induced increases in $S_{\mathrm{I}}$ may be ascribed to training-induced changes in body composition and not to training per se. Supporting this, studies that have compared training with and without weight loss have found much greater improvements in $S_{\mathrm{I}}$ when weight loss is seen $[10,11]$. Moreover, training may fail to improve $S_{\mathrm{I}}$ in individuals with type 2 diabetes who have severe insulin resistance [12].

Like $S_{\mathrm{I}}, S_{\mathrm{G}}$ typically deteriorates with the development of glucose intolerance and type 2 diabetes [13, 14]. However, studies have shown that improvements in $S_{\mathrm{G}}$ over time occur alongside improved glucose tolerance [13], allowing $S_{\mathrm{G}}$ to compensate for insulin resistance and thereby maintaining good glycaemic control [15]. The effect of training on $S_{\mathrm{G}}$ has only been examined in a few studies, which have indicated that training can increase $S_{\mathrm{G}}$ in both healthy $[16,17]$ and obese [18,
19] individuals. To our knowledge, the effects of training on $S_{\mathrm{G}}$ have not previously been assessed in individuals with diabetes. Furthermore, all studies that have evaluated training-induced improvements in $S_{\mathrm{G}}$ have used frequently-sampled IVGTT. This method estimates $S_{\mathrm{I}}$ and $S_{\mathrm{G}}$ by modelling assumptions. While the frequently-sampled IVGTT approach is typically considered a useful tool in healthy, insulin-sensitive individuals, it may be less ideal in insulin-resistant individuals owing to the dynamic nature of the test with transient very high glucose concentrations, which can lead to nonsensical negative values for $S_{\mathrm{I}}$ and concomitant overestimation of $S_{\mathrm{G}}$ [20].

We have previously found that aerobic interval walking training (IWT) is more effective in improving glycaemic control in individuals with type 2 diabetes than energy-expenditurematched continuous walking training (CWT) $[2,21]$. Moreover, we found that IWT-induced improvements in glycaemic control were dependent on improved peripheral tissue glucose disposal [5]. However, since we used hyperglycaemic clamp methodology, it was not possible to determine whether the IWT-induced increments in glucose disposal were dependent on improvements in $S_{\mathrm{I}}$ or $S_{\mathrm{G}}$, or both. As such, the aim of this controlled, crossover study was to assess the efficacy of IWT and CWT in improving $S_{\mathrm{I}}$ and $S_{\mathrm{G}}$ in individuals with type 2 diabetes using direct measurements derived from a two-step (pancreatic and hyperinsulinaemic) hyperglycaemic clamp (Fig. 1). We hypothesised that, in opposition to CWT, IWT would improve the combination of $S_{\mathrm{I}}$ and $S_{\mathrm{G}}$.

\section{Methods}

Fourteen individuals with type 2 diabetes [22] were recruited to the study. Exclusion criteria were exogenous insulin treatment, smoking, pregnancy, contraindications to structured physical activity [23] and participation in recurrent training ( $>90 \mathrm{~min} /$ week). All participants underwent a screening visit including a $\dot{V} \mathrm{O}_{2 \text { peak }}$ test with portable indirect calorimetry equipment (Cosmed K4B2, Cosmed, Rome, Italy). Details of the experimental design have been published elsewhere [21, 24]. All participants gave informed consent. The study was approved by the regional ethical committee (H-6-2014-043) and registered at ClinicalTrials.gov (registration no. NCT02320526).

Study design Participants underwent an experimental day before and after three trials, with each trial including a 2week intervention. The trials were performed in a randomised order, with computer-generated randomisation carried out using www.randomization.com, accessed 6 November 2014 (for reproduction, use seed no. 18512). Wash-out periods ( 8 weeks after the training interventions and 4 weeks after the non-exercise control intervention) were included to ensure that any intervention-induced effects on glucose metabolism had disappeared before the initiation of the next intervention. 
Fig. 1 The two-step (pancreatic and hyperinsulinaemic)

hyperglycaemic clamp procedure used in the study. The pancreatic hyperglycaemic clamp phase is considered to represent $S_{\mathrm{G}}$, and the hyperinsulinaemic

hyperglycaemic clamp phase is considered to represent $S_{\mathrm{G}}+S_{\mathrm{I}}$. As such, $S_{\mathrm{I}}$ is derived by subtracting the results of the pancreatic hyperglycaemic clamp phase from the results of the hyperinsulinaemic hyperglycaemic clamp phase

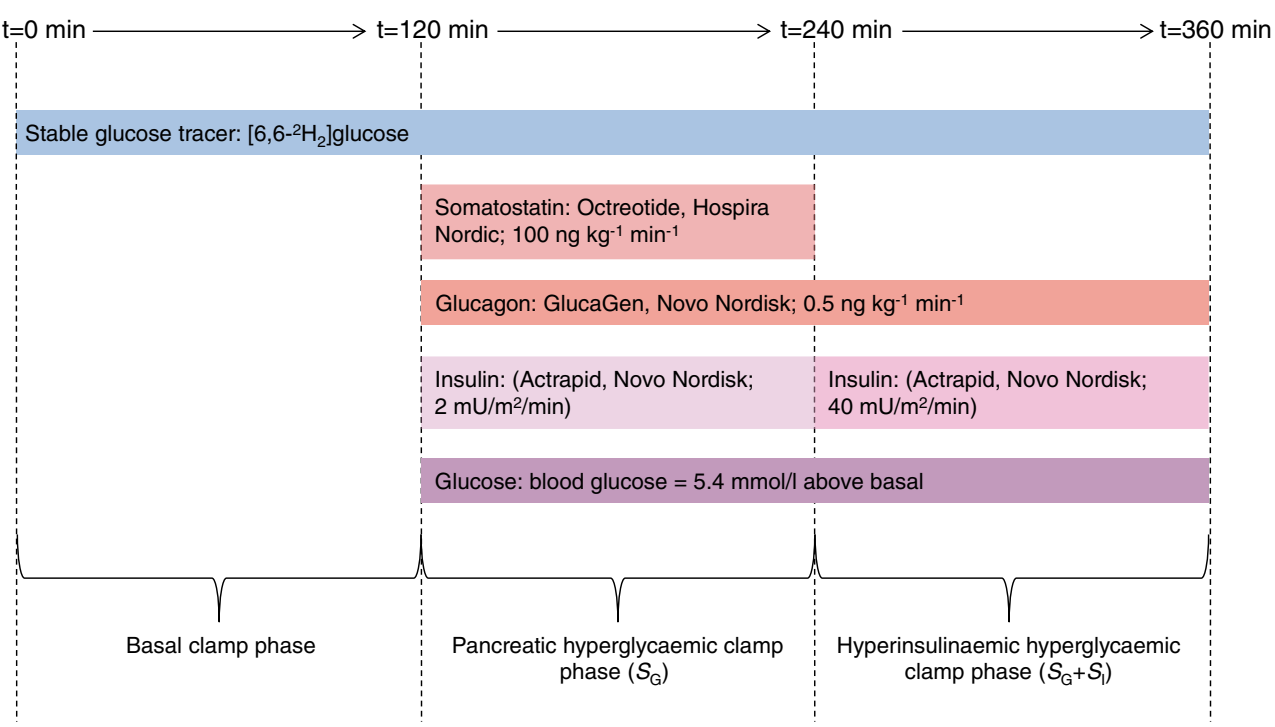

On the experimental days, participants arrived at the laboratory at 07:00 after approximately $12 \mathrm{~h}$ of fasting (water intake was allowed). After voiding, bilateral antecubital vein catheters were inserted and participants were placed in a bed in a temperature-controlled $\left(20^{\circ} \mathrm{C}\right)$ and quiet room, where they stayed for the 360 min clamp procedure (Fig. 1). A primed ( $20 \mu \mathrm{mol} / \mathrm{kg}$ multiplied by fasting glucose, divided by $5 \mathrm{mmol})$, continuous $\left(0.3 \mu \mathrm{mol} \mathrm{kg}{ }^{-1} \mathrm{~min}^{-1}\right)$ infusion of stable $\left[6,6-{ }^{2} \mathrm{H}_{2}\right]$ glucose tracer was initiated at $0 \mathrm{~min}(t=0)$. At $120 \mathrm{~min}$, a basal blood sample was obtained and the pancreatic hyperglycaemic clamp phase began. Infusion of a drug cocktail consisting of somatostatin $\left(100 \mathrm{ng} \mathrm{kg}^{-1} \mathrm{~min}^{-1}\right.$; Octreotide, Hospira Nordic, Stockholm, Sweden), insulin ( $2 \mathrm{mU} / \mathrm{m}^{2} / \mathrm{min}$; Actrapid, Novo Nordisk, Bagsværd, Denmark) and glucagon (0.5 $\mathrm{ng} \mathrm{kg}^{-1} \mathrm{~min}^{-1}$; GlucaGen, Novo Nordisk) commenced and blood glucose levels were increased to $5.4 \mathrm{mmol} / \mathrm{l}$ above the individual's preintervention basal blood glucose level [26] by a square-wave glucose infusion $(100 \mathrm{mg} / \mathrm{ml}$ Glucos Fresenius Kabi, Fresenius Kabi, Uppsala, Sweden) for a 15 min duration. Blood glucose was kept at this hyperglycaemic level for the remainder of the clamp procedure, with glucose infusion rate (GIR) adjustments performed according to a computerised algorithm derived from DeFronzo et al [27] and based on blood glucose measurements obtained every $5 \min$ (ABL 7 series, Radiometer, Herlev, Denmark). At $240 \mathrm{~min}$, the hyperinsulinaemic hyperglycaemic clamp phase commenced. Somatostatin infusion was terminated, glucagon infusion continued unchanged and insulin infusion was initially increased $\left(120 \mathrm{mU} / \mathrm{m}^{2} / \mathrm{min}\right.$ ) and then exponentially decreased (every $1 \mathrm{~min}$ ) over $10 \mathrm{~min}$ to $40 \mathrm{mU} / \mathrm{m}^{2} / \mathrm{min}$ where it remained for the rest of the clamp. At $360 \mathrm{~min}$, the clamp was terminated. Urine from the entire clamp was collected.

Respiratory exchange ratios (RERs) were obtained using indirect calorimetry (Quark, Cosmed) with a ventilated hood. 
Measurements were performed between the 60th and 90th min in each of the three clamp phases (basal; pancreatic hyperglycaemic; hyperinsulinaemic hyperglycaemic), with participants placed in a supine position.

Blood samples for tracer analyses $(\mathrm{NaF}$ tubes) were obtained during fasting (at $0 \mathrm{~min} / t=0$ ) and every $10 \mathrm{~min}$ during the last $30 \mathrm{~min}$ of each clamp phase. Blood samples for analyses of insulin and C-peptide (lithium-heparin tubes), glucagon (EDTA tubes coated with aprotinin $[50 \mathrm{kIU} / \mathrm{ml}]$ ) and NEFA (EDTA tubes) were obtained at the end of each clamp phase. Blood samples were centrifuged $\left(2000 \mathrm{~g}, 15 \mathrm{~min}, 4^{\circ} \mathrm{C}\right)$ and plasma was kept at $-80^{\circ} \mathrm{C}$ until analyses.

After termination of the clamp, participants underwent a dual-energy x-ray absorptiometry scan (Lunar Prodigy Advance, GE 253 Healthcare, Madison, WI, USA).

Analyses Plasma sample tracer enrichment was performed and analysed as previously described [28]. Analyses were performed using an electrochemiluminescence immunoassay (Cobas 8000, Roche Diagnostics, IN, USA) for insulin and Cpeptide, an RIA (GL-32K, Merck Millipore, Darmstadt, Germany) for glucagon and a commercial kit (HR series NEFA-HR(2), Wako Diagnostics, Richmond VA, USA) for NEFA. Urine volume, glucose concentration (ABL 7 series, Radiometer) and urea were measured using absorption photometry (Cobas 8000, Module c702, Roche Diagnostics).

Calculations Mean overall oxygen consumption rates and training-associated RER were calculated, in addition to the mean of the last minute of every fast/slow IWT interval during the first and sixth CWT/IWT sessions for the same variables. Mean heart rates and the mean of the last minute of every fast/slow IWT interval were calculated for all interventions.

Mean GIR was calculated during the last $30 \mathrm{~min}$ of the pancreatic hyperglycaemic and hyperinsulinaemic hyperglycaemic clamp phases. GIR measured during the pancreatic hyperglycaemic clamp phase represents $S_{\mathrm{G}}$ [15], whereas GIR measured during the hyperinsulinaemic hyperglycaemic clamp phase represents a combination of $S_{\mathrm{G}}$ and $S_{\mathrm{I}}[26,29]$. As such, $S_{\mathrm{I}}$ was calculated by subtracting GIR measured during the pancreatic hyperglycaemic clamp phase from GIR measured during the hyperinsulinaemic hyperglycaemic clamp phase.

Total rates of glucose appearance $\left(R_{\text {aTOTAL }}\right)$ and disappearance $\left(R_{\mathrm{d}}\right)$ were assessed using non-steady-state calculations as previously described [30]. Endogenous glucose production ( $R_{\mathrm{aENDO}}$ ) was considered equal to $R_{\mathrm{a}}$ during the basal clamp phase, and was calculated as $R_{\text {aTOTAL }}$ - GIR during the pancreatic and hyperinsulinaemic hyperglycaemic clamp phases. If this resulted in negative values, $R_{\mathrm{aENDO}}$ was set to zero [31].

RER levels obtained during the clamp were used to calculate carbohydrate and lipid oxidation rates, according to the equations by Frayn [32]. Protein oxidation rates were considered stable throughout the clamp procedure and were estimated from the urinary nitrogen excretion derived from urea excretion.

Statistics To assess potential baseline differences, preintervention variables were compared using one-way repeated-measures ANOVA. Variables obtained during the CWT and IWT interventions were compared using Student's paired $t$ test. Variables obtained pre- and postintervention were analysed by two-way repeated-measures ANOVA (intervention $\times$ time) and by one-way repeated-measures ANOVA of the delta (post - pre intervention) values. Comparison of variables between clamp stages was performed using one-way repeated-measures ANOVA. In all ANOVAs, Bonferronicorrected post hoc tests were applied to access specific differences. Regression analyses were used to determine associations between intervention-induced changes in either $S_{\mathrm{G}}$ or $S_{\mathrm{I}}$ and intervention-induced changes in glycaemic control. In the regression analyses including all interventions (where each participant contributed three measurements), adjustments for repeated measures were performed using random-intercept models including participants as random effects. Normality was confirmed using the Shapiro-Wilk test on residuals. Data are reported as means \pm SEM. Statistical tests were performed using Prism v6.03 (GraphPad Software, La Jolla, CA, USA) or Stata v13.1 (StataCorp, College Station, TX, USA), with statistical significance accepted when $p<0.05$.

\section{Results}

All 14 participants ( 11 men, three women; age $65.3 \pm 1.7$ years; time since diabetes diagnosis $8.6 \pm 1.3$ years; BMI $\left.31.6 \pm 1.1 \mathrm{~kg} / \mathrm{m}^{2} ; \mathrm{HbA}_{1 \mathrm{c}} 6.5 \pm 0.2 \%[48 \pm 2 \mathrm{mmol} / \mathrm{mol}]\right)$ continued their usual glucose-lowering treatment (metformin $[n=14]$, sulfonylureas [ $n=3]$, glucagon-like peptide 1 analogues $[n=3]$ ) throughout the study period. The standardised diets were consumed as prescribed prior to each experimental day, resulting in a mean energy intake of $10,117 \pm 418 \mathrm{~kJ}$ with no differences within or between interventions (data not shown). All participants completed all interventions and experimental days. One participant, however, developed fever during the post-IWT experimental day (ear temperature $37.2^{\circ} \mathrm{C}$ before initiation of the clamp and $38.6^{\circ} \mathrm{C}$ at the end of the pancreatic hyperglycaemic clamp phase), and so the clamp was stopped prematurely. As such, this participant was excluded from the analyses and the results include only 13 participants.

Training Adherence to training was high (99\% sessions completed in both the CWT and IWT interventions) and training sessions were, in all cases, completed at the intended 
walking speeds. The CWT and IWT interventions were well matched regarding mean oxygen consumption and heart rates (Table 1), as previously reported [21]. Conversely, mean walking speed was higher and RER was lower in the CWT compared with the IWT intervention.

Body composition and glycaemic control Pre-intervention levels of body composition variables (body mass, fat mass and lean body mass) did not differ between trials. No significant changes within or differences between trials were seen for any body composition variable.

Pre-intervention glycaemic control variables (mean, minimum and maximum CGM glucose levels measured over $24 \mathrm{~h}$ ) did not differ between trials and remained unchanged following the control intervention and CWT. While IWT did not affect minimum 24 h CGM glucose levels, it resulted in a non-significant decrease in mean $24 \mathrm{~h}$ CGM glucose levels $(\Delta=-0.7 \pm 0.2 \mathrm{mmol} / \mathrm{l}$, $p=0.07)$ and significantly decreased maximum $24 \mathrm{~h}$ CGM glucose levels $(\Delta=-1.8 \pm 0.5 \mathrm{mmol} / 1, p<0.05)$.

Body composition and CGM-derived glycaemic control data have been published previously [21].

Table 1 Training variables

\begin{tabular}{lll}
\hline Variable & CWT & IWT \\
\hline $\begin{array}{l}\text { Oxygen uptake (ml/min) } \\
\quad \text { Mean }\end{array}$ & $1524 \pm 78$ & $1513 \pm 78$ \\
$\quad$ Slow-walking intervals & & $1190 \pm 62^{\dagger}$ \\
$\quad$ Fast-walking intervals & & $1814 \pm 99^{\dagger}$ \\
RER (fraction) & & \\
$\quad$ Mean & $0.83 \pm 0.01$ & $0.90 \pm 0.01^{*}$ \\
$\quad$ Slow-walking intervals & & $0.91 \pm 0.01^{\dagger}$ \\
$\quad$ Fast-walking intervals & & $0.90 \pm 0.01^{\dagger}$ \\
Heart rate (beats per min) & & \\
$\quad$ Mean & $108 \pm 3$ & $109 \pm 3$ \\
Slow-walking intervals & & $100 \pm 2^{\dagger}$ \\
$\quad$ Fast-walking intervals & & $119 \pm 3^{\dagger}$ \\
Walking speed (km/h) & & \\
$\quad$ Mean & & $4.7 \pm 0.1^{*}$ \\
Slow-walking intervals & & $3.4 \pm 0.1^{\dagger}$ \\
Fast-walking intervals & & $6.0 \pm 0.1^{\dagger}$ \\
\hline
\end{tabular}

Data are means \pm SEM

Slow-/fast-walking intervals include data from the last minute of each interval

Oxygen uptake and RER data are means of the first and sixth training sessions; all other data are means of all training sessions

Variables were compared using Student's paired $t$ tests

${ }^{*} p<0.05$ CWT vs IWT; ${ }^{\dagger} p<0.05$ IWT slow/fast intervals vs CWT
Clamp details including hormones and metabolites Preintervention levels of blood glucose, insulin, C-peptide, glucagon and NEFA did not differ between trials (Table 2).

Neither basal nor pancreatic/hyperinsulinaemic hyperglycaemic clamp blood glucose concentrations changed with any of the trials, nor were there any intervention-induced differences between trials. Blood glucose concentrations during the clamp were generally stable $(\mathrm{CV}<5 \%)$ with less than $5 \%$ error from the target clamp concentration (Table 2; Fig. 2a).

Insulin concentrations were maintained at basal levels during the pancreatic hyperglycaemic clamp phase with no changes within, nor differences between, trials. Conversely, insulin concentrations were on average approximately sevenfold higher in the hyperinsulinaemic hyperglycaemic clamp phase compared with basal and pancreatic hyperglycaemic clamp phases (both $p<0.001$ ), with no changes within or differences between trials (Fig. 2b).

C-peptide concentrations were reduced in the pancreatic and hyperinsulinaemic hyperglycaemic clamp phases compared with basal (both $p<0.001$ ), with no differences within or between trials and with no differences between the pancreatic and hyperinsulinaemic hyperglycaemic clamp phases (Fig. 2c).

Glucagon concentrations were reduced sequentially from basal to the pancreatic and hyperinsulinaemic hyperglycaemic clamp phases $(p<0.001$ for all comparisons) with no differences within or between trials (Fig. 2d).

NEFA concentrations did not differ within or between trials during any clamp phase. Moreover, NEFA concentrations were not different between baseline and the pancreatic hyperglycaemic clamp phase, but declined from the pancreatic hyperglycaemic clamp phase to the hyperinsulinaemic hyperglycaemic clamp phase $(p<0.001)$.

GIRs and kinetics Pre-intervention GIR, $R_{\mathrm{aENDO}}$ and $R_{\mathrm{d}}$ did not differ between trials in any clamp phase (Table 2).

GIR (Fig. 3a) in the pancreatic hyperglycaemic clamp phase $\left(S_{\mathrm{G}}\right)$ was increased after compared with before IWT $(p<0.05)$, with no intervention-induced effects of the control intervention or CWT and no intervention-induced differences between trials. In the hyperinsulinaemic hyperglycaemic clamp phase $\left(S_{\mathrm{G}}+S_{\mathrm{I}}\right)$, GIR was increased after compared with before IWT $(p<0.01)$, with no intervention-induced effects of the control intervention or CWT and no intervention-induced differences between trials. When subtracting GIR in the pancreatic hyperglycaemic clamp phase from GIR in the hyperinsulinaemic hyperglycaemic clamp phase $\left(S_{\mathrm{I}}\right)$, the significant increase after IWT disappeared, while a nonsignificant increase in GIR after the control intervention was seen $(p=0.10)$; there were still no intervention-induced differences between trials.

In the pancreatic hyperglycaemic clamp phase, no changes within or differences between trials were seen in $R_{\mathrm{d}}$ (Fig. 3b). Conversely, $R_{\mathrm{aENDO}}$ was reduced with CWT $(p<0.05)$ and 
Table 2 Clamp variables

\begin{tabular}{|c|c|c|c|c|c|c|}
\hline \multirow[t]{2}{*}{ Variable } & \multicolumn{2}{|l|}{ Control $^{\mathrm{a}}$} & \multicolumn{2}{|l|}{ CWT } & \multicolumn{2}{|l|}{ IWT } \\
\hline & Pre & Post & Pre & Post & Pre & Post \\
\hline \multicolumn{7}{|l|}{ Basal } \\
\hline Glucose (mmol/l) & $6.9 \pm 0.3$ & $7.3 \pm 0.6$ & $7.2 \pm 0.4$ & $6.9 \pm 0.4$ & $7.4 \pm 0.6$ & $7.0 \pm 0.4$ \\
\hline Insulin (pmol/1) & $106 \pm 12$ & $105 \pm 12$ & $96 \pm 10$ & $94 \pm 15$ & $108 \pm 15$ & $98 \pm 13$ \\
\hline C-peptide (pmol/l) & $1126 \pm 104$ & $1177 \pm 111$ & $1133 \pm 78$ & $1132 \pm 89$ & $1160 \pm 120$ & $1187 \pm 114$ \\
\hline Glucagon (ng/l) & $94 \pm 10$ & $88 \pm 10$ & $92 \pm 8$ & $85 \pm 10$ & $93 \pm 10$ & $86 \pm 8$ \\
\hline$R_{\mathrm{aENDO}}\left(\mathrm{mg} \mathrm{kg}^{-1} \min ^{-1}\right)$ & $1.8 \pm 0.1$ & $1.8 \pm 0.1$ & $1.8 \pm 0.1$ & $1.7 \pm 0.1$ & $1.8 \pm 0.1$ & $1.7 \pm 0.1$ \\
\hline NEFA (mmol/l) & $0.62 \pm 0.03$ & $0.62 \pm 0.05$ & $0.67 \pm 0.06$ & $0.63 \pm 0.04$ & $0.60 \pm 0.05$ & $0.57 \pm 0.05$ \\
\hline RER & $0.82 \pm 0.01$ & $0.82 \pm 0.01$ & $0.80 \pm 0.01$ & $0.80 \pm 0.01$ & $0.82 \pm 0.01$ & $0.81 \pm 0.01$ \\
\hline \multicolumn{7}{|l|}{ Pancreatic hyperglycaemic phase } \\
\hline Glucose (mmol/l) & $12.4 \pm 0.3$ & $12.4 \pm 0.3$ & $12.8 \pm 0.4$ & $12.6 \pm 0.4$ & $12.6 \pm 0.3$ & $12.4 \pm 0.3$ \\
\hline $\mathrm{CV}(\%)$ & $1.4 \pm 0.2$ & $1.1 \pm 0.2$ & $1.4 \pm 0.3$ & $1.4 \pm 0.2$ & $1.2 \pm 0.2$ & $1.0 \pm 0.1$ \\
\hline Deviation from clamp goal (\%) & $1.4 \pm 0.4$ & $1.9 \pm 0.5$ & $3.6 \pm 1.2$ & $1.3 \pm 0.6$ & $2.5 \pm 0.6$ & $1.0 \pm 0.5$ \\
\hline Insulin $(\mathrm{pmol} / \mathrm{l})$ & $95 \pm 18$ & $87 \pm 13$ & $92 \pm 14$ & $84 \pm 13$ & $93 \pm 14$ & $90 \pm 13$ \\
\hline C-peptide (pmol/l) & $707 \pm 99$ & $711 \pm 89$ & $741 \pm 96$ & $690 \pm 76$ & $744 \pm 88$ & $759 \pm 99$ \\
\hline Glucagon (ng/l) & $82 \pm 7$ & $72 \pm 7 *$ & $85 \pm 8$ & $76 \pm 8$ & $85 \pm 6$ & $81 \pm 6$ \\
\hline $\operatorname{GIR}\left(\mathrm{mg} \mathrm{kg}^{-1} \min ^{-1}\right)^{\dagger}$ & $1.2 \pm 0.2$ & $1.1 \pm 0.2$ & $1.1 \pm 0.2$ & $1.2 \pm 0.1$ & $1.0 \pm 0.2$ & $1.5 \pm 0.2 *$ \\
\hline$R_{\mathrm{aENDO}}\left(\mathrm{mg} \mathrm{kg}^{-1} \min ^{-1}\right)^{\ddagger}$ & $1.7 \pm 0.2$ & $1.6 \pm 0.2$ & $1.8 \pm 0.2$ & $1.4 \pm 0.2^{*}$ & $1.7 \pm 0.2$ & $1.4 \pm 0.2^{\S}$ \\
\hline$R_{\mathrm{d}}\left(\mathrm{mg} \mathrm{kg}^{-1} \min ^{-1}\right)$ & $2.9 \pm 0.1$ & $2.7 \pm 0.1$ & $2.8 \pm 0.1$ & $2.6 \pm 0.1$ & $2.7 \pm 0.1$ & $2.9 \pm 0.1$ \\
\hline NEFA (mmol/l) & $0.65 \pm 0.06$ & $0.57 \pm 0.04$ & $0.60 \pm 0.05$ & $0.58 \pm 0.04$ & $0.60 \pm 0.05$ & $0.56 \pm 0.07$ \\
\hline RER & $0.78 \pm 0.01$ & $0.78 \pm 0.01$ & $0.79 \pm 0.01$ & $0.77 \pm 0.01$ & $0.78 \pm 0.01$ & $0.78 \pm 0.01$ \\
\hline \multicolumn{7}{|l|}{ Hyperinsulinaemic hyperglycaemic phase } \\
\hline Glucose (mmol/l) & $12.3 \pm 0.4$ & $12.2 \pm 0.4$ & $12.4 \pm 0.5$ & $12.5 \pm 0.4$ & $12.3 \pm 0.4$ & $12.2 \pm 0.3$ \\
\hline $\mathrm{CV}(\%)$ & $2.1 \pm 0.4$ & $2.2 \pm 0.4$ & $2.0 \pm 0.3$ & $2.1 \pm 0.5$ & $2.3 \pm 0.4$ & $2.4 \pm 0.4$ \\
\hline Deviation from clamp goal $(\%)$ & $-0.2 \pm 0.5$ & $-1.1 \pm 0.6$ & $-1.4 \pm 0.8$ & $-1.1 \pm 0.4$ & $-0.3 \pm 0.6$ & $-0.9 \pm 0.5$ \\
\hline Insulin $(\mathrm{pmol} / \mathrm{l})$ & $729 \pm 38$ & $733 \pm 33$ & $734 \pm 30$ & $713 \pm 33$ & $728 \pm 33$ & $739 \pm 35$ \\
\hline C-peptide (pmol/l) & $698 \pm 101$ & $706 \pm 88$ & $669 \pm 98$ & $712 \pm 92$ & $720 \pm 99$ & $745 \pm 104$ \\
\hline Glucagon (ng/l) & $68 \pm 6$ & $68 \pm 5$ & $75 \pm 7$ & $67 \pm 7$ & $71 \pm 6$ & $68 \pm 6$ \\
\hline $\operatorname{GIR}\left(\mathrm{mg} \mathrm{kg}^{-1} \min ^{-1}\right)^{\dagger \dagger}$ & $4.5 \pm 0.4$ & $5.0 \pm 0.7$ & $4.8 \pm 0.5$ & $5.1 \pm 0.6$ & $5.1 \pm 0.5$ & $6.2 \pm 0.7 * *$ \\
\hline$R_{\mathrm{aENDO}}\left(\mathrm{mg} \mathrm{kg}^{-1} \min ^{-1}\right)$ & $0.0 \pm 0.0$ & $0.0 \pm 0.0$ & $0.0 \pm 0.0$ & $0.0 \pm 0.0$ & $0.0 \pm 0.0$ & $0.0 \pm 0.0$ \\
\hline$R_{\mathrm{d}}\left(\mathrm{mg} \mathrm{kg}^{-1} \min ^{-1}\right)$ & $3.7 \pm 0.2$ & $3.6 \pm 0.3$ & $3.6 \pm 0.2$ & $3.6 \pm 0.3$ & $3.9 \pm 0.3$ & $4.3 \pm 0.3^{*}$ \\
\hline NEFA (mmol/l) & $0.05 \pm 0.01$ & $0.05 \pm 0.01$ & $0.05 \pm 0.01$ & $0.05 \pm 0.01$ & $0.05 \pm 0.01$ & $0.05 \pm 0.01$ \\
\hline RER & $0.85 \pm 0.01$ & $0.86 \pm 0.01$ & $0.85 \pm 0.01$ & $0.84 \pm 0.02$ & $0.84 \pm 0.01$ & $0.86 \pm 0.01$ \\
\hline
\end{tabular}

Data are means \pm SEM during the second-to-last (RER) and last 30 min of the clamp stages (glucose, CV, error from clamp goal, GIR, $R_{\mathrm{a}}$ and $R_{\mathrm{d}}$ ) or at the end of the clamp stage (insulin, C-peptide, glucagon and NEFA)

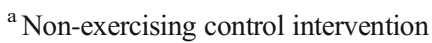

${ }^{*} p<0.05, * * p<0.01$ (within group, pre vs post); ${ }^{\dagger} p<0.05$ (time $\times$ group interaction); ${ }^{\ddagger} p<0.05$ (main effect of time); ${ }^{\S} p=0.07$ (within group, pre vs post)

was non-significantly decreased with IWT $(p=0.07)$. No changes were seen within the control intervention or between trials (Fig. 3c).

In the hyperinsulinaemic hyperglycaemic clamp phase, $R_{\mathrm{d}}$ increased following IWT $(p<0.05)$, whereas no changes within CWT or the control intervention and no differences between trials were seen (Fig. $3 \mathrm{~b}$ ). $R_{\mathrm{aENDO}}$ was maximally suppressed in almost all participants in the hyperinsulinaemic hyperglycaemic clamp phase, and no differences within or between trials were seen (Fig. 3c).

When subtracting $R_{\mathrm{d}}$ in the pancreatic hyperglycaemic clamp phase from $R_{\mathrm{d}}$ in the hyperinsulinaemic hyperglycaemic clamp phase, the significant improvement as a result of IWT disappeared, and no differences within or between trials were seen (Fig. 3b). Since the calculated $R_{\mathrm{aENDO}}$ was negative in several hyperinsulinaemic hyperglycaemic clamp phases and therefore 
a
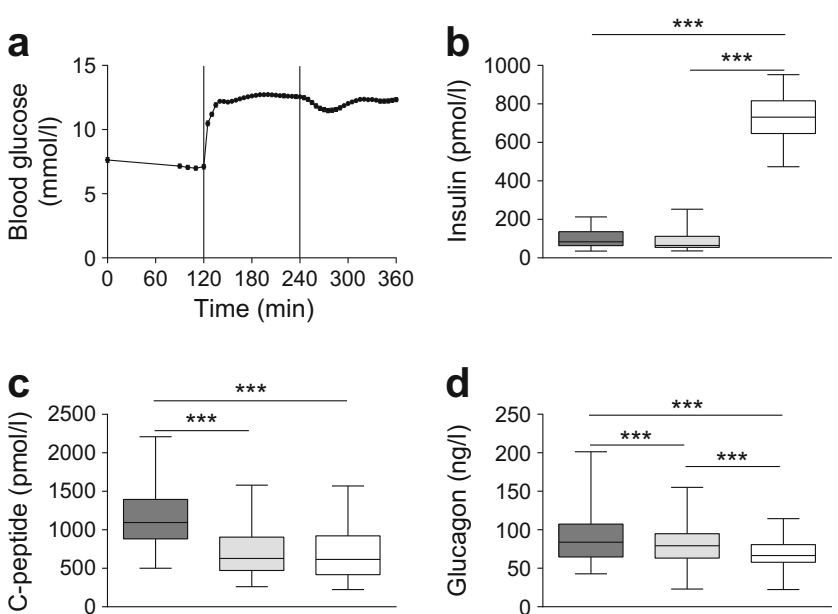

Fig. 2 Blood glucose (a), insulin (b), C-peptide (c) and glucagon (d) concentrations during the hyperglycaemic clamp. Dark grey boxes, basal (0-120 min); light grey boxes, pancreatic hyperglycaemic clamp phase (120-240 $\mathrm{min}$ ); white boxes, hyperinsulinaemic hyperglycaemic clamp phase (240-360 min). Since no differences were seen within or between trials, data are presented as means \pm SEM (a) and box and whisker plots (b-d) of all clamps. Statistical differences were analysed using one-way repeated-measures ANOVA between clamp stages. $* * * p<0.001$

set to zero, the subtraction of $R_{\mathrm{aENDO}}$ during the pancreatic hyperglycaemic clamp phase from the hyperinsulinaemic hyperglycaemic phase was not performed (Fig. 3c). Since $S_{\mathrm{G}}$, as described above, is defined as the ability of glucose per se to stimulate its own uptake and suppress its own production [7], we subtracted $R_{\mathrm{aENDO}}$ from $R_{\mathrm{d}}$ in the pancreatic hyperglycaemic clamp phase. This resulted in an increase after IWT and an intervention-induced difference between the control intervention and IWT ( $p<0.05$ for both).

Clamp RER and substrate oxidation rates Pre-intervention levels of RER and substrate oxidation rates did not differ in any clamp phase between trials, and no changes within or differences between trials were seen in basal levels or during the pancreatic hyperglycaemic clamp phase (Table 2, Fig. 3d, e). In the hyperinsulinaemic hyperglycaemic clamp phase, carbohydrate oxidation rates non-significantly increased with IWT $(p=0.10)$, whereas fat oxidation rates decreased $(p<0.05)$. No IWT-induced changes were seen in protein oxidation rates, and no interventioninduced changes in RER or any substrate oxidation rates were seen in the control intervention or CWT. When subtracting the pancreatic clamp phase from the hyperinsulinaemic clamp phase, no changes within or differences between trials were seen for RER or substrate oxidation rates.

\section{Associations between intervention-induced changes in} glycaemic control and $S_{\mathrm{G}}$ or $S_{\mathrm{I}}$ When evaluating all trials collectively, significant associations between changes in GIR in the pancreatic hyperglycaemic clamp phase $\left(S_{\mathrm{G}}\right)$ and changes in mean $\left(\beta=-0.62 \pm 0.23, r^{2}=0.17\right.$, $p<0.01$, Fig. 4a) and maximum $(\beta=-1.18 \pm 0.52$, $r^{2}=0.12, p<0.05$, Fig. 4b) 24 h CGM glucose were seen, whereas no association was found for minimum
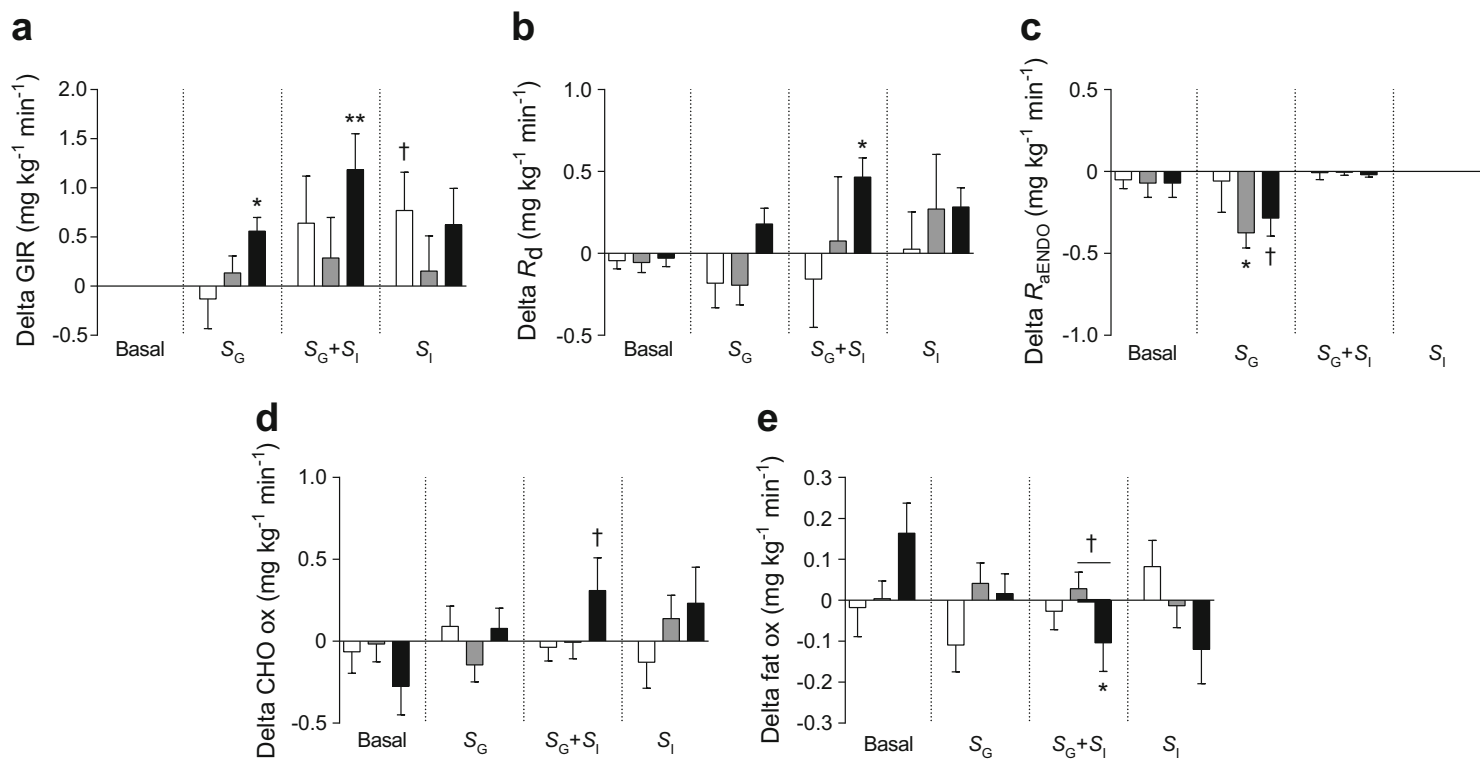

Fig. 3 Delta (post - pre intervention) values for GIR (a), $R_{\mathrm{d}}(\mathbf{b}), R_{\mathrm{aENDO}}$ (c), and carbohydrate oxidation ( $\mathrm{CHO}$ ox; $\mathbf{d}$ ) and fat oxidation (fat ox; $\mathbf{e}$ ) rates. Each graph is subdivided into the basal clamp phase, the pancreatic hyperglycaemic $\left(S_{\mathrm{G}}\right)$ clamp phase, the hyperinsulinaemic hyperglycaemic $\left(S_{\mathrm{G}}+S_{\mathrm{I}}\right)$ clamp phase and the hyperinsulinaemic minus pancreatic $\left(S_{\mathrm{I}}\right)$ clamp phase. Since the calculated $R_{\mathrm{aENDO}}$ was negative in several hyperinsulinaemic hyperglycaemic clamp phases and, therefore, set to zero, subtraction of $R_{\mathrm{aENDO}}$ during the pancreatic hyperglycaemic

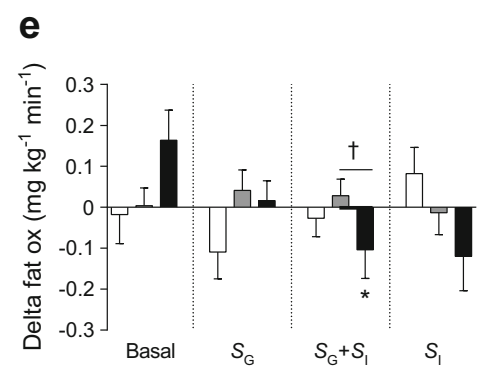

clamp phase from the hyperinsulinaemic hyperglycaemic phase was not performed. White bars, control (no exercise); grey bars, CWT; black bars, IWT. Data are presented as mean delta values \pm SEM. Statistical differences were analysed using two-way (intervention $\times$ time) repeated-measures ANOVA for within-intervention, within-clamp-phase comparisons and by one-way repeated-measures ANOVA for between-intervention, within-clamp-phase comparisons (indicated by a connecting line between bars). ${ }^{*} p<0.05, * * p<0.01,{ }^{\dagger} p \leq 0.10$ 
Fig. 4 Associations between delta (post - pre intervention) values in $S_{\mathrm{G}}$ and mean and maximum 24 h CGM glucose levels $(\mathbf{a}, \mathbf{b})$ and delta values in $S_{\mathrm{I}}$ and mean and maximum $24 \mathrm{~h}$ CGM glucose levels (c, d). Circles, control intervention; squares, CWT; triangles, IWT. Associations were examined using linear regression analyses, with $r$ and $p$ values given in the figure
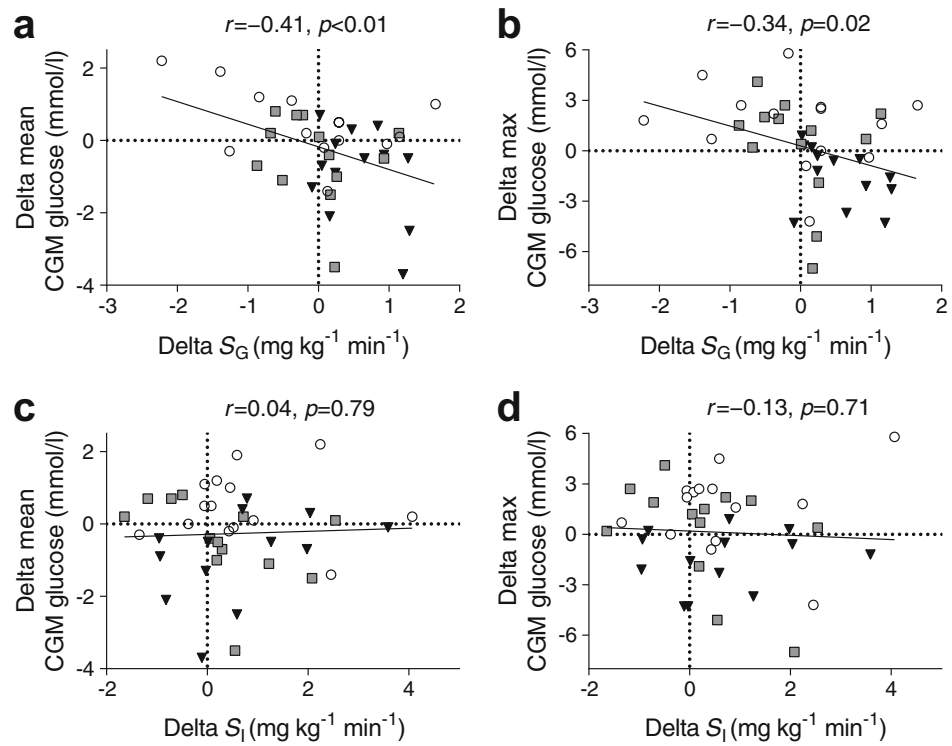

24 h CGM glucose $(p>0.05)$. Conversely, no associations were seen between changes in GIR in the hyperinsulinaemic hyperglycaemic clamp phase minus the pancreatic hyperglycaemic clamp phase $\left(S_{\mathrm{I}}\right)$ and any glycaemic control variable (Fig. 4c, d).

When evaluating the IWT trial alone, the associations between changes in $S_{\mathrm{G}}$ and changes in mean $(\beta=-0.89 \pm 0.71$, $\left.r^{2}=0.13, p>0.05\right)$ and maximum $(\beta=-1.40 \pm 0.96$, $\left.r^{2}=0.16, p>0.05\right) 24 \mathrm{~h}$ CGM glucose retained $\beta$ coefficients and $r^{2}$ values comparable with those of the analyses including all trials, but were no longer significant.

\section{Discussion}

This is the first study to assess training-induced changes in both $S_{\mathrm{G}}$ and $S_{\mathrm{I}}$ in individuals with type 2 diabetes. Several findings are to be highlighted. First, $S_{\mathrm{G}}$ increased significantly following 2 weeks of IWT in individuals with type 2 diabetes, whereas $S_{\mathrm{I}}$ did not. Second, intervention-induced changes in $S_{\mathrm{G}}$ but not $S_{\mathrm{I}}$ were associated with changes in CGM-derived glycaemic control. Third, the IWT-induced increase in $S_{\mathrm{G}}$ was dependent on the combination of increased glucose disposal and decreased endogenous glucose production. Fourth, whereas 2 weeks of CWT reduced endogenous glucose production in response to hyperglycaemia with basal levels of insulin, no overall CWT-induced changes in $S_{\mathrm{G}}$ or $S_{\mathrm{I}}$ were seen.

The associations seen between intervention-induced changes in $S_{\mathrm{G}}$ and the mean and maximum $24 \mathrm{~h}$ CGM glucose levels indicate that $S_{\mathrm{G}}$ is an important determinant of glycaemic control in individuals with type 2 diabetes. Since no associations were observed between changes in $S_{\mathrm{I}}$ and either the mean or the maximum $24 \mathrm{~h}$ CGM glucose level, increases in $S_{\mathrm{G}}$ may be the most important determinant of short-term training-induced improvements in glucose tolerance in individuals with type 2 diabetes. Interestingly, $S_{\mathrm{G}}$ only increased with IWT but not with CWT, highlighting that peak exercise intensity is important for improvements in $S_{\mathrm{G}}$, which is in accord with previous findings [33]. Whereas the associations between changes in $S_{\mathrm{G}}$ and CGM glucose levels were not significant when evaluating only the IWT trial, the associations retained comparable $\beta$-coefficients and $r^{2}$ values as when all trials were included in the regression analyses. As such, at least parts of the IWT-induced improvements in glycaemic control were probably mediated via $S_{\mathrm{G}}$.

The IWT-induced improvements in $S_{\mathrm{G}}$ were reflected neither by significantly reduced endogenous glucose production nor by increased glucose disposal, but rather by the combined effects of the two. Whereas this may be related to low power, we speculate that individual differences may be responsible, with some individuals responding to hyperglycaemia with reduced endogenous glucose production and other individuals with increased glucose disposal. Type 2 diabetes is a highly heterogeneous disease [34], and responses to exercise are therefore expected to be heterogeneous, as previously demonstrated $[16,35,36]$.

The mechanisms underlying the IWT-induced improvements in $S_{\mathrm{G}}$ cannot readily be determined from this study. It has been proposed that impaired $S_{\mathrm{G}}$ in individuals with type 2 diabetes is dependent on increased systemic concentrations of NEFA [37], and that normalisation of NEFA concentrations near-normalises $S_{\mathrm{G}}[14,38]$. However, we did not find any effect of the training interventions on NEFA concentrations, suggesting that NEFA is not important for the IWT-improved $S_{\mathrm{G}}$. Other mechanistic suggestions of importance for $S_{\mathrm{G}}$ include the mass action effect of glucose, glucose-induced stimulation of enzymatic activity in skeletal muscle and liver 
and a direct effect of glucose in promoting GLUT4 translocation to the cell membrane in skeletal muscle [7, 15]. Since liver enzyme content and activity can hardly be assessed in human in vivo studies, future studies evaluating traininginduced effects on $S_{\mathrm{G}}$ should consider using animal models.

It is generally accepted that physical activity can acutely increase peripheral tissue glucose disposal for up to $48 \mathrm{~h}$, and that this may be mediated both via insulin-dependent and insulin-independent mechanisms [39, 40]. Several insulinindependent mechanisms responsible for acute exerciseinduced peripheral tissue disposal have been identified, with AMP-activated protein kinase (AMPK) [41] and Ras-related C3 botulinum toxin substrate 1 [42] being key players. Since our clamp procedure was initiated $39-43 \mathrm{~h}$ after the last CWT/ IWT exercise bout, we cannot rule out that acute exercise effects might have played a role in the IWT-induced improvements seen in $S_{\mathrm{G}}$, since these mechanisms are known to be dependent on exercise intensity [43].

Another factor that might have played a role in the difference in $S_{\mathrm{G}}$ after CWT vs IWT is the difference in RER during the training sessions. The increased RER during IWT indicates that a larger fraction of the substrates used during IWT was derived from carbohydrates. Therefore, glycogen depletion in skeletal muscle was probably higher following IWT than CWT. Since skeletal muscle glycogen depletion provides a strong stimulus for increased peripheral tissue glucose disposal [44], this may have influenced the differences found. In addition, since carbohydrate oxidation rates during the pancreatic hyperglycaemic clamp phase were not increased by IWT (Fig. 3b), non-oxidative glucose disposal (glycogen synthesis and storage) might have been increased. However, the approximately $40 \mathrm{~h}$ time window between the last exercise bout and the clamp procedure, during which participants consumed a mixed diet, should have been sufficient to replenish skeletal muscle glycogen levels. This is, however, speculation and should be confirmed prospectively.

The lack of significant improvements in $S_{\mathrm{I}}$ with the training interventions must be noted. Since both CWT and IWT numerically increased both $S_{\mathrm{I}}$ and the associated glucose disposal, the lack of significance may potentially be ascribed to low power and the unexpected (and unexplainable) borderline significant increase in $S_{\mathrm{I}}$ after the control intervention. Nonetheless, the increases in $S_{\mathrm{I}}$ following our training interventions were small, particularly when compared with other studies of short-term training interventions [45, 46]. Since training interventions without changes in body composition improve $S_{\mathrm{I}}$ less than training interventions with improved body composition [10], and since training-induced improvements in $S_{\mathrm{I}}$ are typically undetectable $48 \mathrm{~h}$ after the last exercise bout when no changes in body composition are seen [47, 48], our study design likely explains the lack of improvement in $S_{\mathrm{I}}$. Of interest, previous findings have indicated that, whereas training-induced improvements in $S_{\mathrm{I}}$ are short-lived, training-induced improvements in $S_{\mathrm{G}}$ are maintained for at least 1 week after training cessation [17].

It must be noted that the one-way repeated-measures ANOVA analyses performed on the delta values did not result in any between-trial differences in $S_{\mathrm{G}}$ or $S_{\mathrm{I}}$. Given the observed within-trial differences in the two-way repeatedmeasures ANOVA analyses, we hypothesise that the small sample size may explain the lack of between-trial differences. As such, future studies must use larger sample sizes in order to assess potential differences between interventions. Moreover, it must be noted that the non-simultaneous measurement of $S_{\mathrm{G}}$ and $S_{\mathrm{G}}+S_{\mathrm{I}}$ may potentially be a problem when $S_{\mathrm{I}}$ is derived. This may be explained by the fact that $S_{\mathrm{I}}$ (assessed by GIR in a euglycaemic-hyperinsulinaemic clamp) typically increases with increasing clamp duration [49]. Although we are not aware of studies evaluating the effect of increased time duration on $S_{\mathrm{G}}$, it may be questioned whether $S_{\mathrm{G}}$ in the hyperinsulinaemic hyperglycaemic clamp phase was the same as during the pancreatic hyperglycaemic clamp phase. That said, by using state-of-the-art and high-quality glucose clamp methodology, we believe that our study advances the field with novel observations regarding glycaemic adaptations following exercise in diabetes.

In conclusion, this study has shown that short-term IWT improves $S_{\mathrm{G}}$ but not $S_{\mathrm{I}}$ in individuals with type 2 diabetes. Moreover, changes in $S_{\mathrm{G}}$ but not $S_{\mathrm{I}}$ are associated with changes in glycaemic control. As such, $S_{\mathrm{G}}$ is an important yet underappreciated mechanism by which training may influence glucose metabolism, and future studies should evaluate the importance and underlying mechanisms of training-induced improvements in $S_{\mathrm{G}}$.

Acknowledgements R. Rovsing, H. Villumsen, L. Foged, M. G. Høiberg, L. Kjølbo, I. A. Müller, L. S. Hansen, S. Thorsen and C. K. Olsen (The Centre for Physical Activity Research [CFAS], Rigshospitalet, Denmark) are acknowledged for their technical assistance. M. Ried-Larsen (CFAS) is acknowledged for statistical assistance.

Data availability The data that support the findings of this study are available on request from the corresponding author (KK), given that this does not violate the laws of the Danish Data Protection Agency.

Funding CFAS is supported by a grant from TrygFonden. During the study period, the Centre of Inflammation and Metabolism (CIM) was supported by a grant from the Danish National Research Foundation (DNRF55). The study was further supported by grants from Diabetesforeningen, Augustinusfonden and Krista og Viggo Petersens Fond. CIM/CFAS is a member of DD2 - the Danish Center for Strategic Research in Type 2 Diabetes (the Danish Council for Strategic Research, grant no. 09-067009 and 09-075724).

Duality of interest The authors declare that there is no duality of interest associated with this manuscript. 
Contribution statement $\mathrm{KK}$ designed the study and obtained the funding. TPJS and BKP contributed to the study design. KK, MAC, IJ and SHK acquired the data. KK, MAC, GvH and TPJS analysed and interpreted the data. KK wrote the manuscript. All authors reviewed and revised the manuscript and approved the final version. $\mathrm{KK}$ is the guarantor for the work as a whole.

\section{References}

1. Umpierre D, Ribeiro PA, Kramer CK et al (2011) Physical activity advice only or structured exercise training and association with HbAlc levels in type 2 diabetes: a systematic review and metaanalysis. JAMA 305:1790-1799

2. Karstoft K, Winding K, Knudsen SH et al (2013) The effects of free-living interval-walking training on glycemic control, body composition, and physical fitness in type 2 diabetes patients. Diabetes Care 36:228-236

3. Healy GN, Dunstan DW, Shaw JE, Zimmet PZ, Owen N (2006) Beneficial associations of physical activity with 2-h but not fasting blood glucose in Australian adults: the AusDiab study. Diabetes Care 29:2598-2604

4. Richter EA, Hargreaves M (2013) Exercise, GLUT4, and skeletal muscle glucose uptake. Physiol Rev 93:993-1017

5. Karstoft K, Winding K, Knudsen SH et al (2014) Mechanisms behind the superior effects of interval vs continuous training on glycaemic control in individuals with type 2 diabetes: a randomised controlled trial. Diabetologia 57:2081-2093

6. Kahn SE, Prigeon RL, McCulloch DK et al (1994) The contribution of insulin-dependent and insulin-independent glucose uptake to intravenous glucose tolerance in healthy human subjects. Diabetes 43:587-592

7. Dube S, Errazuriz-Cruzat I, Basu A, Basu R (2015) The forgotten role of glucose effectiveness in the regulation of glucose tolerance. Curr Diab Rep 15:605

8. Richter EA, Garetto LP, Goodman MN, Ruderman NB (1982) Muscle glucose metabolism following exercise in the rat: increased sensitivity to insulin. J Clin Invest 69:785-793

9. Way KL, Hackett DA, Baker MK, Johnson NA (2016) The effect of regular exercise on insulin sensitivity in type 2 diabetes mellitus: a systematic review and meta-analysis. Diabetes Metab J 40:253-271

10. Coker RH, Williams RH, Yeo SE et al (2009) The impact of exercise training compared to caloric restriction on hepatic and peripheral insulin resistance in obesity. J Clin Endocrinol Metab 94:4258-4266

11. Albu JB, Heilbronn LK, Kelley DE et al (2010) Metabolic changes following a 1-year diet and exercise intervention in patients with type 2 diabetes. Diabetes 59:627-633

12. Burns N, Finucane FM, Hatunic M et al (2007) Early-onset type 2 diabetes in obese white subjects is characterised by a marked defect in beta cell insulin secretion, severe insulin resistance and a lack of response to aerobic exercise training. Diabetologia 50:1500-1508

13. Lorenzo C, Wagenknecht LE, Karter AJ, Hanley AJ, Rewers MJ, Haffner SM (2011) Cross-sectional and longitudinal changes of glucose effectiveness in relation to glucose tolerance: the insulin resistance atherosclerosis study. Diabetes Care 34:1959-1964

14. Kishore P, Tonelli J, Koppaka S et al (2006) Time-dependent effects of free fatty acids on glucose effectiveness in type 2 diabetes. Diabetes 55:1761-1768

15. Best JD, Kahn SE, Ader M, Watanabe RM, Ni TC, Bergman RN (1996) Role of glucose effectiveness in the determination of glucose tolerance. Diabetes Care 19:1018-1030

16. Boule NG, Weisnagel SJ, Lakka TA et al (2005) Effects of exercise training on glucose homeostasis: the HERITAGE family study. Diabetes Care 28:108-114
17. Nishida Y, Tokuyama K, Nagasaka S et al (2004) Effect of moderate exercise training on peripheral glucose effectiveness, insulin sensitivity, and endogenous glucose production in healthy humans estimated by a two-compartment-labeled minimal model. Diabetes 53:315-320

18. AbouAssi H, Slentz CA, Mikus CR et al (2015) The effects of aerobic, resistance, and combination training on insulin sensitivity and secretion in overweight adults from STRRIDE AT/RT: a randomized trial. J Appl Physiol (1985) 118:1474-1482

19. Coen PM, Tanner CJ, Helbling NL et al (2015) Clinical trial demonstrates exercise following bariatric surgery improves insulin sensitivity. J Clin Invest 125:248-257

20. Muniyappa R, Lee S, Chen H, Quon MJ (2008) Current approaches for assessing insulin sensitivity and resistance in vivo: advantages, limitations, and appropriate usage. Am J Physiol Endocrinol Metab 294:E15-E26

21. Karstoft K, Clark MA, Jakobsen I et al (2017) The effects of 2 weeks of interval vs continuous walking training on glycaemic control and whole-body oxidative stress in individuals with type 2 diabetes: a controlled, randomised, crossover trial. Diabetologia 60:508-517

22. Ryden L, Grant PJ, Anker SD et al (2013) ESC guidelines on diabetes, pre-diabetes, and cardiovascular diseases developed in collaboration with the EASD: the task force on diabetes, pre-diabetes, and cardiovascular diseases of the European Society of Cardiology (ESC) and developed in collaboration with the European Association for the Study of diabetes (EASD). Eur Heart J 34:3035-3087

23. Pedersen BK, Saltin B (2015) Exercise as medicine - evidence for prescribing exercise as therapy in 26 different chronic diseases. Scand J Med Sci Sports 25(Suppl 3):1-72

24. Karstoft K, Brinklov CF, Thorsen IK, Nielsen JS, Ried-Larsen M (2017) Resting metabolic rate does not change in response to different types of training in subjects with type 2 diabetes. Front Endocrinol (Lausanne) 8:132

25. Mifflin MD, St Jeor ST, Hill LA, Scott BJ, Daugherty SA, Koh YO (1990) A new predictive equation for resting energy expenditure in healthy individuals. Am J Clin Nutr 51:241-247

26. Elahi D (1996) In praise of the hyperglycemic clamp. A method for assessment of beta-cell sensitivity and insulin resistance. Diabetes Care 19:278-286

27. DeFronzo RA, Tobin JD, Andres R (1979) Glucose clamp technique: a method for quantifying insulin secretion and resistance. Am J Phys 237:E214-E223

28. Borno A, Foged L, van Hall G (2014) Glucose and glycerol concentrations and their tracer enrichment measurements using liquid chromatography tandem mass spectrometry. J Mass Spectrom 49:980-988

29. Vind BF, Birk JB, Vienberg SG et al (2012) Hyperglycaemia normalises insulin action on glucose metabolism but not the impaired activation of AKT and glycogen synthase in the skeletal muscle of patients with type 2 diabetes. Diabetologia 55:1435-1445

30. Plomgaard P, Bouzakri K, Krogh-Madsen R, Mittendorfer B, Zierath JR, Pedersen BK (2005) Tumor necrosis factor- $\alpha$ induces skeletal muscle insulin resistance in healthy human subjects via inhibition of Akt substrate 160 phosphorylation. Diabetes 54: 2939-2945

31. Wolfe RR, Chinkes DL (2005) Isotope tracers in metabolic research: principles and practice of kinetic analysis (second edn). Wiley, Hoboken

32. Frayn KN (1983) Calculation of substrate oxidation rates in vivo from gaseous exchange. J Appl Physiol 55:628-634

33. Hayashi $\mathrm{Y}$, Nagasaka S, Takahashi $\mathrm{N}$ et al (2005) A single bout of exercise at higher intensity enhances glucose effectiveness in sedentary men. J Clin Endocrinol Metab 90:4035-4040

34. DeFronzo RA (2009) Banting lecture. From the triumvirate to the ominous octet: a new paradigm for the treatment of type 2 diabetes mellitus. Diabetes 58:773-795 
35. Solomon TP, Malin SK, Karstoft K, Haus JM, Kirwan JP (2013) The influence of hyperglycemia on the therapeutic effect of exercise on glycemic control in patients with type 2 diabetes mellitus. JAMA Intern Med 173:1834-1836

36. Solomon TP, Malin SK, Karstoft K, Kashyap SR, Haus JM, Kirwan JP (2013) Pancreatic $\beta$-cell function is a stronger predictor of changes in glycemic control after an aerobic exercise intervention than insulin sensitivity. J Clin Endocrinol Metab 98:4176-4186

37. Hawkins M, Gabriely I, Wozniak R, Reddy K, Rossetti L, Shamoon H (2002) Glycemic control determines hepatic and peripheral glucose effectiveness in type 2 diabetic subjects. Diabetes 51:2179-2189

38. Hawkins M, Tonelli J, Kishore P et al (2003) Contribution of elevated free fatty acid levels to the lack of glucose effectiveness in type 2 diabetes. Diabetes 52:2748-2758

39. Holloszy JO (2005) Exercise-induced increase in muscle insulin sensitivity. J Appl Physiol 99:338-343

40. Sylow L, Kleinert M, Richter EA, Jensen TE (2017) Exercisestimulated glucose uptake-regulation and implications for glycaemic control. Nat Rev Endocrinol 13:133-148

41. Steinberg GR, Kemp BE (2009) AMPK in health and disease. Physiol Rev 89:1025-1078

42. Sylow L, Jensen TE, Kleinert M et al (2013) Rac1 is a novel regulator of contraction-stimulated glucose uptake in skeletal muscle. Diabetes 62:1139-1151
43. Sriwijitkamol A, Coletta DK, Wajcberg E et al (2007) Effect of acute exercise on AMPK signaling in skeletal muscle of subjects with type 2 diabetes: a time-course and dose-response study. Diabetes 56:836-848

44. Jensen J, Rustad PI, Kolnes AJ, Lai YC (2011) The role of skeletal muscle glycogen breakdown for regulation of insulin sensitivity by exercise. Front Physiol 2:112

45. O'Gorman DJ, Karlsson HK, McQuaid S et al (2006) Exercise training increases insulin-stimulated glucose disposal and GLUT4 (SLC2A4) protein content in patients with type 2 diabetes. Diabetologia 49:2983-2992

46. Kirwan JP, Solomon TP, Wojta DM, Staten MA, Holloszy JO (2009) Effects of 7 days of exercise training on insulin sensitivity and responsiveness in type 2 diabetes mellitus. Am J Physiol Endocrinol Metab 297:E151-E156

47. Ross R, Janssen I, Dawson J et al (2004) Exercise-induced reduction in obesity and insulin resistance in women: a randomized controlled trial. Obes Res 12:789-798

48. Oshida Y, Yamanouchi K, Hayamizu S, Nagasawa J, Ohsawa I, Sato Y (1991) Effects of training and training cessation on insulin action. Int J Sports Med 12:484 486

49. Hojlund K, Staehr P, Hansen BF et al (2003) Increased phosphorylation of skeletal muscle glycogen synthase at NH2terminal sites during physiological hyperinsulinemia in type 2 diabetes. Diabetes 52:1393-1402 